\title{
ENSINO E AUTORIA: SOBRE A ELABORAÇÃO DE MATERIAL DIDÁTICO PARA UM CURSO DE PRODUÇÃO ORAL NO PROGRAMA ISF
}

Teaching and authorship: on teaching material development for an oral production course at the LwB Program

\section{Cristiane Carvalho de Paula BRITO* Pedro Henrique SILVEIRA**}

\begin{abstract}
RESUMO: Este trabalho visa discutir resultados parciais de um projeto de desenvolvimento de material didático para ensino de língua inglesa, em um NucLi do Programa Idiomas sem Fronteiras (ISF) de uma universidade pública mineira. Mais especificamente interessa-nos: (i) apresentar os objetivos e a forma de implementação do referido projeto; (ii) descrever e analisar a produção do material didático para o curso de Produção Oral: Entrevistas; e (iii) problematizar as percepções da coordenadora pedagógica e dos professores bolsistas do programa acerca da experiência de elaboração de material. A produção do material didático, bem como o olhar que agora lançamos ao projeto, é balizada por uma concepção enunciativodiscursiva de linguagem e pelos estudos em Linguística Aplicada. Nossas análises sugerem que a elaboração do material didático se constitui como processo tenso-conflitivo de produção e resistência, ao demandar dos professores bolsistas a inscrição em distintas posições discursivas, a saber: a de professores de língua inglesa e a de produtores de material.

PALAVRAS-CHAVE: Formação de ABSTRACT: This work aims to discuss partial results from an English teaching material development project in a Language Center of the Language without Borders Program (LwB) from a public university in the state of Minas Gerais. We are more specifically interested in: (i) presenting the objectives of the project and the way it was implemented; (ii) analysing the production of teaching material for the course Oral Production: Interviews; and (iii) problematizing the perceptions of both the pedagogical coordinator and the student teachers concerning the experience of material development. The development of the teaching materials and our current view of the project rely on an enunciative and discursive conception of language and on the studies of Applied Linguistics. Our analyses suggest that the development of teaching material is a tense and conflicting process of both production and resistance since it demands from teachers the inscription in distinct discursive positions, namely: the position of English teacher and that of writer of teaching materials.

KEYWORDS: Teacher education; teaching material development; English teaching.
\end{abstract} professores; material didático; ensino de língua inglesa.

\footnotetext{
* Doutora em Linguística Aplicada pela Universidade Estadual de Campinas (2009). Docente na Universidade Federal de Uberlândia (UFU). Coordenadora pedagógica, bolsista CAPES, do Programa Idiomas sem Fronteiras - NucLi-IsF/UFU.

** Licenciado em Letras-Inglês pela Universidade Federal de Uberlândia (UFU). Professor, bolsista CAPES, do Programa Idiomas sem Fronteiras - NucLi-IsF/UFU.
} 


\section{Introdução}

O Programa Idiomas sem Fronteiras ${ }^{1}$ (ISF) foi criado em 2012 com o propósito de auxiliar estudantes de nível superior a desenvolverem proficiência linguística em inglês, a fim de terem acesso ao Ciências sem Fronteiras.

Atualmente o Programa está presente na quase totalidade das universidades federais do país, em várias estaduais e em muitos institutos federais, tendo como principal objetivo promover ações em prol de uma política linguística para a internacionalização do Ensino Superior Brasileiro e oferecer residência docente para os futuros profissionais do ensino de línguas estrangeiras.

O ISF tem na formação especializada de professores de línguas estrangeiras (LE) um de seus pilares (KIRSCH; SARMENTO, 2018; SARMENTO; ABREU-E-LIMA; MORAES FILHO, 2016; SARMENTO; KIRSCH, 2015). Além da ministração de aulas de línguas estrangeiras (LE) com fins acadêmicos, da aplicação de testes de proficiência à comunidade universitária, da organização de eventos acadêmico-culturais, dentre outras atividades, os professores trabalham na produção de material didático para os diversos cursos em que atuam.

Neste artigo, discutiremos resultados parciais de um projeto de desenvolvimento de material didático de língua inglesa (LI), no NucLi-ISF/UFU². Mais especificamente interessanos: (i) apresentar os objetivos e implementação do referido projeto; (ii) descrever e analisar a produção do material didático para o curso de Produção Oral: Entrevistas; e (iii) problematizar as percepções da coordenadora pedagógica e dos professores bolsistas acerca da experiência de elaboração do material.

Fazemos coro com as palavras de (2008), ao afirmar que

A produção de materiais especialmente preparados para situações específicas de aprendizagem tem sido indicada como a mais eficaz para se atenderem às necessidades psicológicas e sociais de diferentes tipos de alunos. A contribuição de uma abordagem instrumental de ensino de línguas, tanto materna quanto estrangeira deu especial contribuição para este aspecto. Isto, no entanto, esbarra na questão da formação do professor que deve estar preparado não só para analisar seu contexto específico de trabalho, mas também para ele mesmo confeccionar os materiais mais adequados para aquele contexto. (CELANI, 2008, p. 29-30)

\footnotetext{
${ }^{1}$ Inicialmente, o Programa foi denominado de Inglês sem Fronteiras, pois focava apenas no ensino da língua inglesa. Em 2014, passa a ser denominado Programa Idiomas sem Fronteiras, com a abertura para outras línguas estrangeiras.

${ }^{2}$ Os Núcleos de Línguas ISF são compostos por coordenadores (geral e pedagógicos) e professores bolsistas, graduandos ou graduados, com licenciatura em Letras Inglês.
} 
Brito; Silveira | p. 44- $60 \quad$ Ensino e autoria: Sobre a elaboração de material didático para um curso...

Nesse sentido, o Programa ISF contribui para a formação profissional do professor na medida em que lhe permite experienciar a produção de materiais didáticos de ensino de línguas estrangeiras para fins acadêmicos, tendo em vista as especificidades dos diversos cursos por eles ministrados. A produção do material didático, ao posicionar o professor no lugar de autor, permite-lhe deslocamentos discursivos e subjetivos em sua relação com a língua que ensina-aprende. A escrita se configura como instância que instaura um lugar de enunciação em que o sujeito precisa tomar um posicionamento diante de seu objeto de ensino, tornando-o acessível ao outro. Tal processo demanda do professor-autor decisões acerca, por exemplo, dos objetivos, temas, atividades, textos e layout de seu material didático. Nesse sentido, defendemos que a própria escrita se torna uma instância de formação profissional (MELO et al, 2013, BRITO, 2012; FIAD, 2011;), abrindo espaço para o (des)arranjo da complexa rede de sentidos que interpelam os sujeitos.

A produção do material didático, bem como o olhar que agora lançamos aos resultados parciais do projeto, é balizada por uma concepção enunciativa-discursiva de linguagem, em especial pelas concepções teóricas do Círculo de Bakhtin (BAKHTIN/VOLOCHINOV, 1929/2002; BAKHTIN, 2002; 1953/2003;), as quais intentamos alinhavar ao longo da discussão aqui proposta para compreender e investigar a relação sujeito-linguagem-escrita. Ademais, ancoramo-nos nos estudos em Linguística Aplicada (FABRÍCIO, 2017; GUILHERME, 2013; CELANI, 2008; MOITA LOPES, 2006), os quais ressaltam a importância de se considerar a linguagem como prática social, histórica, ideológica, situada, heterogênea e multimodal, e o ensino-aprendizagem de línguas como processo que visa a problematização de noções homogeneizantes e totalitárias de conhecimento.

Para responder aos objetivos propostos, organizamos este artigo da seguinte forma: além desta introdução e das considerações finais, explicitamos, primeiramente, o projeto de desenvolvimento de material didático proposto em nosso $\mathrm{NucLi}$; em seguida, descrevemos e analisamos o material elaborado para o curso de Produção Oral: Entrevistas; e, por fim, discutimos as percepções da coordenadora pedagógica e dos professores bolsistas acerca do referido projeto.

\section{Sobre o projeto de desenvolvimento de material didático no NucLi-UFU/GEISF}

$\mathrm{O}$ projeto de produção de material didático se configura como uma das atividades desenvolvidas no âmbito do NucLi-UFU, dentro do Grupo de Estudos do Idiomas sem 
Fronteiras (GEISF). Apesar de ser uma atividade prevista no programa ${ }^{3}$, entendemos que sua formalização como um projeto contribui para dar visibilidade a uma proposta orientada por um arcabouço teórico-metodológico balizado por uma noção de linguagem como prática sócio-ideológica e discursiva, além de criar, no referido NucLi, um plano de ações e metas que intentam contribuir para o desenvolvimento acadêmico-profissional dos professores bolsistas. Desse modo, o projeto se justifica pela necessidade de produzir material didático para ensino de inglês com fins acadêmicos, no contexto do Programa Idiomas sem Fronteiras, que seja responsivo às demandas e interesses locais e que enseje a tomada significante da palavra pelo sujeito brasileiro falante de inglês.

De forma mais específica, intentamos: (i) desenvolver material didático para os diversos cursos de LI implementados no Programa Idiomas sem Fronteiras, a partir de uma perspectiva enunciativa-discursiva de linguagem; (ii) investigar a utilização do material didático desenvolvido em aulas ministradas pelos professores bolsistas de LI participantes do Programa, no que diz respeito ao desenvolvimento linguístico-discursivo e crítico dos alunos em LI; e (iii) encorajar a prática reflexiva de professores de LI em formação. Em termos gerais, o material didático pode ser definido como tudo aquilo que contribua para a aprendizagem (TOMLINSON, 2012; SALAS, 2004). Todavia, ressaltamos que aqui tomamos material didático como a sistematização, em formato de apostila, de uma proposta didática para o ensino de inglês com fins acadêmicos.

Para dar início ao projeto ${ }^{4}$, dividimos os professores bolsistas e os English Teaching Assistants (ETA) ${ }^{5}$ em 3 grupos e estabelecemos as seguintes etapas:

1. Análise dos planos dos $\operatorname{cursos}^{6}$ de Produção oral: entrevistas; Produção oral: interações acadêmicas e Compreensão oral: palestras e aulas, a fim de identificar seus principais objetivos e aspectos linguísticos, discursivos e culturais ${ }^{7}$;

2. Elaboração, pelos grupos, de situações comunicativas e levantamento de gêneros discursivos relacionados aos objetivos dos cursos selecionados;

\footnotetext{
${ }^{3}$ Uma das atribuições dos professores bolsistas, conforme o termo de compromisso dos bolsistas, é "conhecer o material didático que compõe a base do curso on-line e desenvolver materiais didáticos ou atividades complementares de ensino de língua específica nas modalidades presencial e a distância, sob a forma de tutoria ou coaching".

${ }_{5}^{4} \mathrm{O}$ projeto foi formalizado, no âmbito do NucLI-UFU, no primeiro semestre de 2018.

5 No início do desenvolvimento do projeto, o NucLi-UFU contava com a participação de três EnglishTeachingAssistants, bolsistas americanos da Fullbright.

${ }^{6}$ Os cursos oferecidos pelos NucLi de língua inglesa são selecionados a partir de um catálogo de cursos formalizados pelo núcleo gestor do Programa ISF.

${ }^{7}$ Cada grupo ficou responsável por analisar um curso.
} 
Brito; Silveira | p. 44- $60 \quad$ Ensino e autoria: Sobre a elaboração de material didático para um curso...

3. Produção de possíveis diálogos para as situações comunicativas apontadas; e

4. Produção de uma unidade para o curso.

As três primeiras etapas cumpriram o objetivo de sensibilizar os professores acerca da necessidade de se estudar e compreender as especificidades dos cursos escolhidos, de forma a encorajá-los a pensar em práticas de linguagem possíveis de serem desenvolvidas, a partir da proposta de cada curso, no contexto de sala de aula. Ao solicitarmos que os professores elencassem situações comunicativas e gêneros discursivos relacionados a esses cursos, pudemos explorar a noção de língua(gem) como prática social, situada e concreta. Trata-se da compreensão de que

Aprender a falar significa aprender a construir enunciados (porque falamos por enunciados e não por orações isoladas e, evidentemente, não por palavras isoladas). Os gêneros do discurso organizam o nosso discurso quase da mesma forma que o organizam as formas gramaticais (sintáticas). Nós aprendemos a moldar o nosso discurso em formas de gênero e, quando ouvimos o discurso alheio, já adivinhamos o seu gênero pelas primeiras palavras, adivinhamos certo volume (isto é, uma extensão aproximada do conjunto do discurso), uma determinada construção composicional, prevemos o fim, isto é, desde o início temos a sensação do conjunto do discurso que, em seguida, apenas se diferencia no processo da fala. (BAKHTIN, 2016, p. 39)

Desse modo, pudemos problematizar noções mais estruturalistas que tomam a linguagem apenas em seus aspectos formais, resultando no ensino de meras formas gramaticais descontextualizadas, a fim de chamar a atenção para o caráter social e dialógico de uma perspectiva que compreende a linguagem - e a produção de sentidos - como sempre atrelados aos processos de enunciação.

Um aspecto relacionado a esse e que também guiou a discussão, no grupo, foi a necessidade de se contemplar o 'conflito' na tomada da palavra. Entendemos que a tomada da palavra é sempre tenso-conflitiva por mobilizar diferentes vozes que habitam os sujeitos, distintas filiações discursivas, haja vista que a palavra é o "fenômeno ideológico por excelência" (BAKHTIN/VOLOCHINOV, 1929/2002, p. 41). Ao encorajar os professores a considerarem o 'conflito', em suas propostas pedagógicas, defendemos um processo de ensino-aprendizagem que refuta uma noção de língua como mero instrumento de comunicação para compreendê-la como materialidade simbólica que (des)constrói identidades, nos processos enunciativos, sempre mobilizados por relações de poder. 
Hashiguti (2013), ao analisar imagens de corpos e rostos em livros didáticos e seus efeitos para os processos de aprendizagem, argumenta que pode se observar um

movimento de regularização do que pode ser um imaginário proposto pelos livros: a de falantes da língua inglesa que são predominantemente alegres, e numa relação metonímica, a de uma língua em que se pode ser feliz. Discursivamente, a língua estrangeira aparece pouco relacionada à discussão de problemas sociais, situações difíceis que envolvam temas considerados talvez mais delicados, como a morte, os desastres naturais, as questões políticas, guerras, confrontos, pobreza e exclusão, que também acontecem na e pela língua inglesa. (HASHIGUTI, 2013, p. 50-51)

Apesar de as análises da autora se referirem a livros didáticos para ensino de LI geral, entendemos que esse imaginário constitui uma memória discursiva acerca do que seja ensinaraprender LI que talvez incida ainda mais fortemente no ensino de inglês para fins acadêmicos, uma vez que este é tradicionalmente visto como mera transmissão de habilidades ou conteúdo específico de uma língua para outra.

Pennycook (1994) critica o que denomina de futilitarianism na área de English for Academic Purposes (EAP). Segundo o autor, há dois grandes desafios a serem enfrentados pela área, a saber: a questão do conteúdo dos cursos, que tende a adquirir o caráter de futilidade (futility), haja vista a superficialidade com que muitas temáticas são tratadas nas aulas; e a visão utilitária (utilitarianism) que lhe é tradicionalmente atribuída devido ao seu papel como prestadora de serviço a outras disciplinas. Para Pennycook, tais desafios se assentam na crença de que o inglês seria um veículo neutro para se atingir propósitos acadêmicos e na de que a língua seria um meio pelo qual sentidos são expressos. Ele chama a atenção para a necessidade de se desenvolverem perspectivas mais críticas no ensino de línguas para fins acadêmicos, a fim de mudar a ideologia acomodacionista que permeia o EAP, que, por sua vez, pressupõe a simples assimilação da vida acadêmica pelos alunos.

Nesse sentido, contemplar, nos materiais didáticos, situações de conflito abre a possibilidade para que o aluno brasileiro de LI possa dizer(-se) na língua estrangeira, em situações de interação acadêmica, de forma a não apenas acomodar-se ao(s) outro(s), mas a também resistir, subverter, questionar discursos hegemônicos construídos na/pela língua.

Após a apresentação inicial do projeto, utilizamos as reuniões pedagógicas ${ }^{8}$ para o desenvolvimento, propriamente dito, do material. Em grupos, os professores discutiram e decidiram acerca dos objetivos, temas para as unidades, textos orais e escritos para compor o

\footnotetext{
${ }^{8}$ As reuniões pedagógicas do NucLi-ISF/UFU acontecem semanalmente para a discussão de textos teóricos, planejamento de aulas, organização de eventos acadêmico-culturais etc.
} 
Brito; Silveira | p. 44- $60 \quad$ Ensino e autoria: Sobre a elaboração de material didático para um curso...

material, tipos de atividades, layout, dentre outros. As reuniões foram feitas no laboratório do curso de Letras, possibilitando, assim, que os professores acessassem a internet e fizessem pesquisas de textos, imagens, vídeos, aspectos lexicais, dentre outras.

Nessa primeira fase do projeto, os alunos desenvolveram esboços das unidades que deveriam compor cada um dos três cursos selecionados. Apenas o material para o curso de Produção Oral: Entrevistas foi finalizado. Passamos agora à sua descrição e análise.

\section{Material Didático para o curso de Produção Oral: Entrevistas}

O material elaborado no projeto foi desenvolvido pelo segundo autor deste artigo, bolsista no NucLi-ISF-UFU, para o curso de Produção Oral: Entrevistas, nível A2, de acordo com o Quadro Comum Europeu, e foi idealizado de modo que pudesse abranger cursos de 16 e/ou 32 horas. A apostila foi dividida em três grandes seções: livro do aluno, seção extra e livro de exercícios. O livro do aluno foi dividido em 8 unidades, sendo que cada unidade foi nomeada com uma pergunta a fim de despertar os conhecimentos prévios e experiências dos alunos, a partir da temática abordada.

Em linhas gerais, a primeira unidade, intitulada Canyoutell me aboutyourself?,oferece aos alunos a oportunidade de se apresentarem em LI de acordo com o contexto de entrevistas. What are your experiences? é o nome da segunda unidade, cujo foco é possibilitar ao aluno a reflexão de suas experiências acadêmicas e profissionais que são importantes e relevantes de serem mencionadas nos diversos contextos de entrevistas. A terceira unidade se chama Have you ever been interviewed? e permite ao aluno pensar sobre as características dos gêneros entrevista acadêmica e entrevista profissional. Na quarta unidade - Are you good at solving puzzles? - o objetivo principal é que o aluno tenha contato com os diversos tipos de entrevista e trabalhe com vídeos de candidatura, as suas características e a sua relevância nos processos seletivos atuais. Na unidade seguinte, intitulada Can you choose it without bias?, os alunos podem discutir os desafios dos momentos de escolha, em uma entrevista. A sexta unidade se chama How honest are you? e abre espaço para a discussão sobre a necessidade ou não de ser honesto durante um processo seletivo, bem como para o reconhecimento das qualidades e aspectos a serem melhorados, em termos profissionais e pessoas. Can you handle it? é o nome da sétima unidade, que reflete sobre a habilidade de contar histórias durante uma entrevista, considerando quais deverão ser os aspectos para esta história e que tipo de história é válido para o contexto em questão. A última unidade se chama Are you ready for it? e se constitui de 
Brito; Silveira | p. 44- $60 \quad$ Ensino e autoria: Sobre a elaboração de material didático para um curso...

um apanhado do que foram as outras unidades, além de discutir a questão da ansiedade no contexto de entrevistas e formas de se amenizá-la. Vale ressaltar que toda unidade presente no livro do aluno começa com uma atividade de elucidação do conteúdo principal da aula. Geralmente são atividades lúdicas que fazem referência ao que será discutido no decorrer da unidade.

A seção extra se divide em duas partes e se constitui de propostas de situações práticas no contexto do curso que não foram abordadas dentro das unidades. A primeira parte se chama Got to be real, que é referente a situações reais, mas que geralmente não são discutidas quando tratamos de entrevistas, tais como uma situação de doença, o imprevisto do telefone tocar durante um processo seletivo, a questão dos costumes locais, dentre outras. O objetivo desta seção é oferecer ao aluno a percepção de que tais situações podem acontecer e explorar formas de enfrentá-las na/pela língua alvo. A segunda parte contempla uma situação comunicativa em que há a necessidade de se cancelar uma entrevista por um motivo qualquer, que se enquadra nas situações não rotineiras sobre entrevistas de emprego. Embora esta eventualidade possa acontecer por telefone, trabalhamos com a escrita de e-mail para oferecer ao aluno a oportunidade de reconhecer o gênero e-mail formal e, ao mesmo tempo, trabalhar uma questão de conflito no uso da língua.

A terceira seção do material é um livro de exercícios, desenvolvido a partir das dificuldades linguísticas e gramaticais percebidas pelo professor durante as aulas. Sendo assim, esta seção se torna uma oportunidade para o aluno explorar, fora ou dentro de sala de aula, aspectos da língua inglesa que lhe darão um suporte maior ao enunciar comunicativamente. Cada tema da seção do livro de exercícios se relaciona às unidades do livro do aluno. Esta seção possui um caráter gradativo, começando por exercícios mais fechados e centrados na estrutura da língua até exercícios que oferecem ao aluno a oportunidade de reflexão e produção escrita. As atividades do livro de exercícios foram elaboradas para que os alunos pudessem fazê-los em casa e discuti-los em sala com professores e colegas. No entanto, estas atividades podem ser adaptadas para a sala de aula em cursos com a carga horária maior, como exemplo os cursos de 32 horas.

Devido à limitação de espaço, apresentaremos algumas amostras da apostila, seguidas de comentários, em quadros, que explicitem nossas análises, a partir da perspectiva teórica que balizou o desenvolvimento do material. 


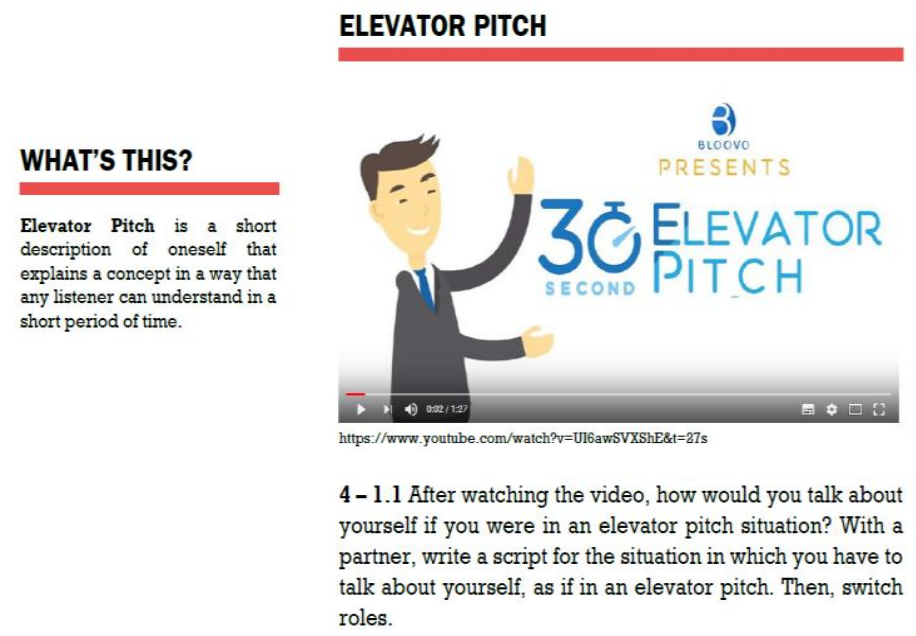

Figura 1. Unidade 1: Can you tell me about yourself? Fonte: os autores
Por meio do conceito de Elevator Pitch, tenta-se dar ao aluno a possibilidade de se dizer na LI, trazendo à tona sentidos que o interpelam a(o) falar de si, o que, a nosso ver, abre espaço para a emergência da subjetividade, por meio de processos de identificação com as diferentes vozes sócioideológicas e históricas que constituem os sujeitos.

\section{MY UNIVERSITY EXPERIENCE}

TIPS

We use the past tense to talk about things we accomplished. Pay attention to the use of verb tenses and the past form of verbs.

Figura 2. Unidade 2: What are your experiences? Fonte: os autores
5 - 2.1 Listen to Kyle talking about his university experiences. Name 3 interesting facts about his time in university.

6 - Listen to the audio again. What are the advantages of his university? What are the advantages of your university?

1-Do you have any similar experience? If so, which one?

$\mathrm{Na}$ unidade 2, contamos com a participação de um dos ETA, que gravou um áudio relatando suas experiências universitárias. A atividade trouxe a possibilidade de discutir diferenças culturais no âmbito acadêmico. Neste momento especificamente, houve também a possibilidade de participação do ETA no curso em questão, o que abriu espaço para que a questão cultural fosse colocada em alteridade, e não apenas sob uma perspectiva que prioriza o falante/língua/cultura nativos. 


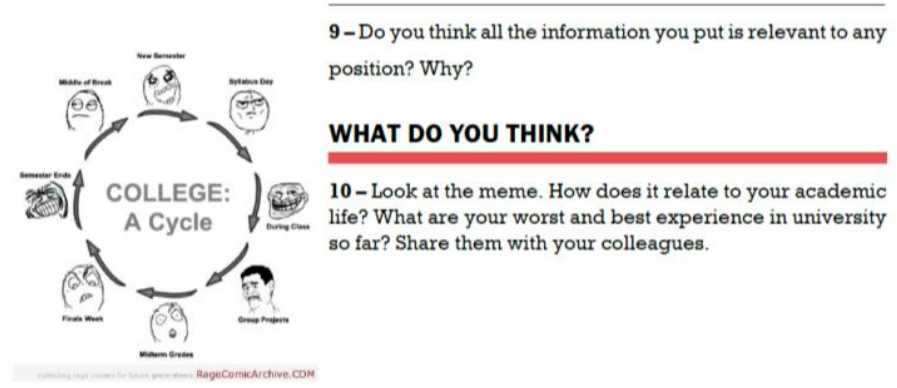

Figura3. Unidade 2: What are your experiences?

Fonte: os autores
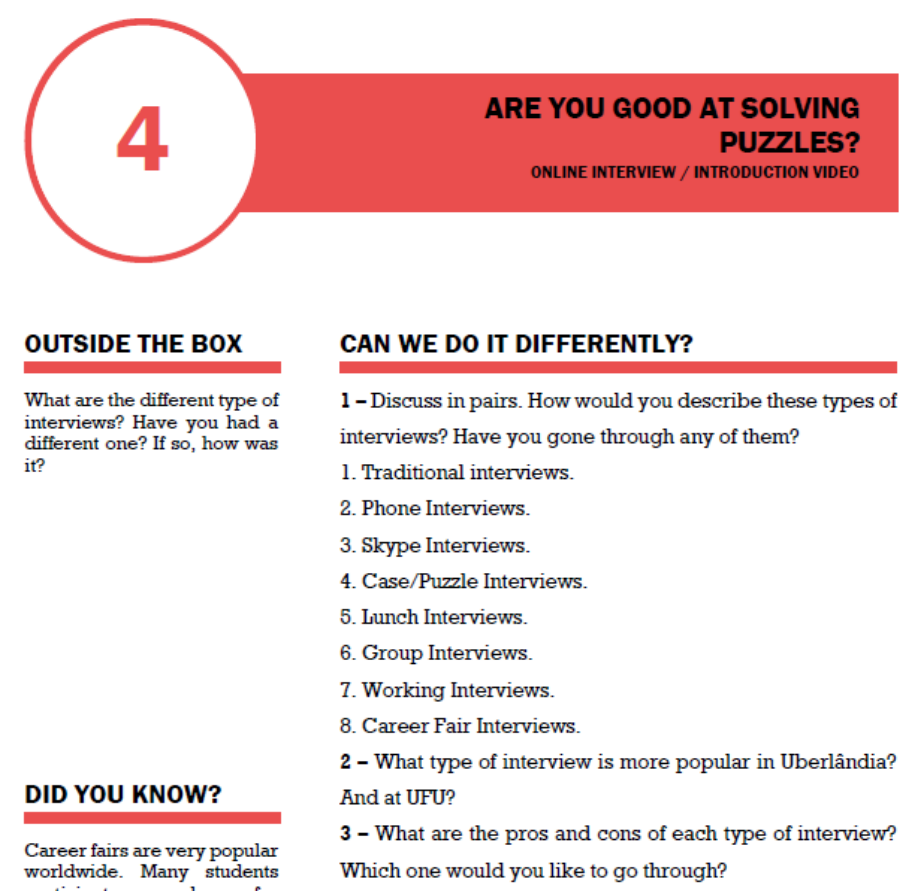

Figura 4. Unidade 4: Are you good at solving puzzles? Fonte: os autores

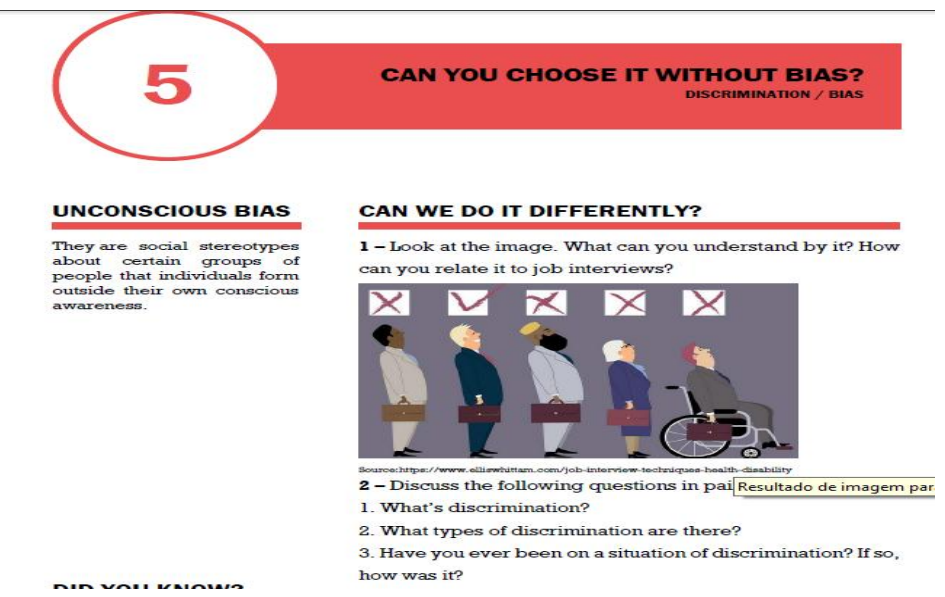

Figura5. Unidade5: Can you choose it without bias? Fonte: os autores

Olhares \& Trilhas | Uberlândia $\mid$ vol.20, n. 3 set/dez.
Ainda na unidade 2, exploramos o posicionamento do aluno acerca de sua vida acadêmica, a partir de um meme. $\mathrm{O}$ intuito é trabalhar a língua em seu aspecto multimodal, de forma a possibilitar o engajamento do aluno em práticas discursivas que

Na unidade 4, foram trabalhadas as diferenças entre diversos tipos de entrevista de forma a sensibilizar os alunos para as especificidades linguísticas, discursivas, bem como culturais entre eles. Além disso, ao questionar o aluno sobre entrevistas mais comuns em sua cidade e universidade, tenta-se

Na unidade 5, a partir de um
cartoon, pudemos discutir a
questão da discriminação e
problematizar estereótipos
culturais, raciais, étnicos etc., bem
como formas de resistência a eles
na/pela LE. Trata-se de abordar a
língua, de forma a refutar visões
que lhe atribuem status de
neutralidade.
(neutral 
Brito; Silveira | p. 44- $60 \quad$ Ensino e autoria: Sobre a elaboração de material didático para um curso...

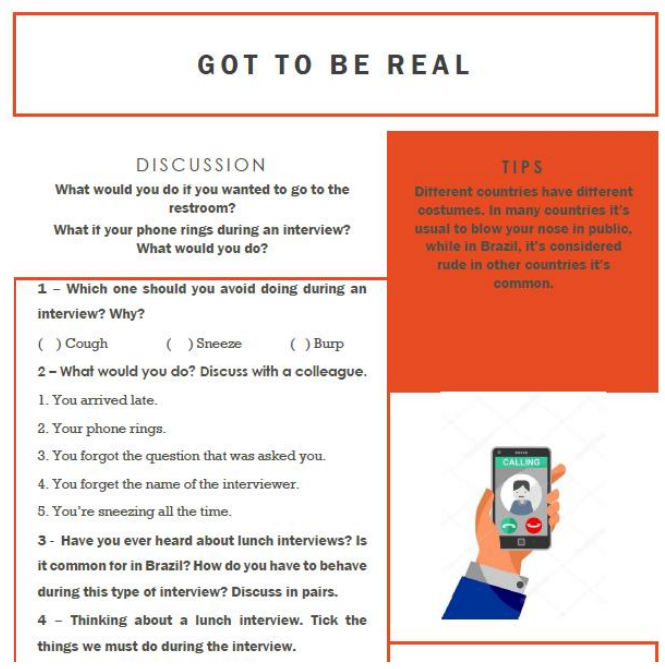

Figura 6. Seção extra - Parte 1. Fonte: os autores

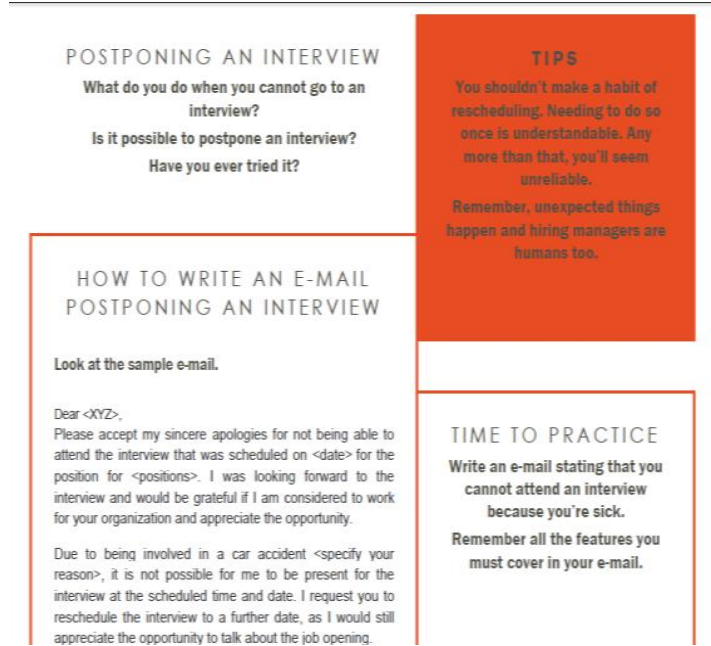

Figura 7. Seção extra - Parte 2. Fonte: os autores

$\mathrm{Na}$ seção extra, exploramos possíveis situações de conflito, em entrevistas, possibilitando ao aluno que se posicione tanto pela produção oral quanto escrita na LI. Trata-se de se aventar uma concepção de língua e de ensino-aprendizagem como prática social e situada, permeada por relações de poder entre os interlocutores. Trata-se ainda de encorajar o falante brasileiro de LI a se ver como enunciador legítimo de uma língua outra, mesmo que não a domine em seus aspectos formais.

Ressaltamos que o material ainda está em fase de revisão, e que a ideia é desenvolver uma proposta que esteja sempre aberta a reformulações, tanto no que diz respeito aos textos trabalhados, aos tipos de atividades, à integração de ferramentas digitais, sobretudo para encorajar a autonomia do aluno e o estudo da LI fora da sala de aula. Ainda não foi possível elaborar uma seção voltada para a avaliação de cada unidade, com critérios definidos acerca dos aspectos pelos quais a performance linguística-discursiva do alunos deva ser avaliada. De qualquer forma, entendemos que a proposta até o momento tenha conseguido contemplar as inquietações teórico-pedagógicas discutidas no NucLi, sobretudo a de se promover um ensino-aprendizagem que leve em consideração as necessidades e interesses locais, sem desconsiderar as demandas globais para o uso da língua. Enfim, uma proposta que tome a língua e seu ensino como fenômeno responsivo à vida social.

Passamos agora à discussão das percepções dos professores bolsistas e da coordenadora pedagógica acerca do projeto. 
Brito; Silveira | p. 44- $60 \quad$ Ensino e autoria: Sobre a elaboração de material didático para um curso...

\section{Percepções sobre o projeto: a escrita entre a produção e a resistência}

Nesta seção, discutimos, com base na análise das respostas dos professores a um questionário avaliativo e de notas de campo da coordenadora, suas percepções sobre o desenvolvimento do projeto de produção de material didático até o momento. Nossa análise se pauta em uma metodologia qualitativa, na qual nos interessa delinear as vozes que são evocadas pelos professores ao atribuírem sentido à experiência de elaborar material didático, bem como discutir o efeito de nossas observações como coordenadora pedagógica. A nosso ver, o projeto instaurou, aos professores, tanto um gesto de produção quanto de resistência pela/na escrita.

Ao serem solicitados a responder um questionário avaliativo sobre as atividades desenvolvidas no NucLi-UFU no primeiro semestre de 2018, os professores se posicionaram acerca do projeto de desenvolvimento de material didático, ao responderem à pergunta: Como você avalia o primeiro semestre de 2018, em relação às reuniões e atividades pedagógicas? Trazemos, no Quadro 1 abaixo, alguns excertos representativos das respostas dadas por eles para discussão de suas percepções.

\section{Quadro 1: Avaliação dos professores bolsistas}

$\mathrm{P}^{9}{ }^{9}$ : Estou gostando da elaboração de material didático em pequenos grupos, é uma forma de aprendermos uns com os outros e trocar experiências. Creio que aprendemos mais trabalhando em grupo.

P2: As atividades de desenvolvimento de material didático foram muito importante para mim, pois percebi que eu poderia criar e nortear os meus cursos através destes materiais.

P3: Achei bastante interessante. Nunca havia trabalhado dessa forma, principalmente na questão de produção de material didático. Acredito que realmente nos ajuda na vida como professores, pois nos dá novas ideias e nos faz ter um novo olhar sobre certas coisas.

P4: Além disso, as reuniões pedagógicas para elaboração de material didático foram uma ótima ideia na minha opinião e gostaria que acontecessem de novo, pois é um momento em que podemos dividir ideias e opiniões.

P5: Acho que o que salvou nossas reuniões pedagógicas foi a oficina de material didático.

\footnotetext{
${ }^{9}$ Os professores serão representados pela letra ' $\mathrm{P}$ ' e um número. Ressaltamos que o questionário foi respondido por 10 professores bolsistas.

Olhares \& Trilhas | Uberlândia | vol.20, n. 3 | set/dez. 2018 - ISSN 1983-3857
} 
Não gosto de trabalho em grupo no que tange o planejamento de material/cursoe eu seria mais produtiva se houvesse a opção de produzir isso sozinha, mas ao mesmo tempo entendo a intenção por trás do trabalho em grupo e lhe dou devida importância.

De forma geral, o projeto de produção de material didático parece ter sido bem recebido pelos professores. Em seus dizeres, destacam-se a relevância do trabalho colaborativo (P1), a contribuição para a preparação das aulas (P2) e o (re)posicionamento como professor (P3). Todavia, vê-se também a dissonância de vozes, no dizer de P5, para quem o projeto em si foi significativo, mas não a experiência de produzir em grupo.

Uma outra forma de avaliação do projeto se deu pelas notas de campo da coordenadora pedagógica. Trata-se de observações a respeito dos posicionamentos dos professores durante as reuniões do grupo e de seu envolvimento nos momentos de produção do material, propriamente dito. Organizamos nossas percepções por meio de enunciados que expressam, em nosso gesto de leitura, o efeito de sentido dos dizeres de alguns professores acerca da relevância do projeto. Vejamos.

i) A questão da 'pertinência': representada pelo enunciado o material didático pode engessar as aulas;

ii) A questão da 'eficiência': expressa no enunciado o material didático só pode ser eficientemente usado pelo próprio professor que o produziu;

iii) A questão da 'redundância': representada por já produzo material didático.

$\mathrm{O}$ primeiro enunciado - o material didático pode engessar as aulas - trouxe à baila a questão da pertinência de se elaborar material didático, haja vista que isso poderia tornar as aulas repetitivas, engessadas e não pertinentes aos diferentes contextos de ensinoaprendizagem. Tal enunciado parece evocar a voz da crítica aos livros didáticos como instrumentos que limitam a autonomia do professor em sala de aula. Sem desconsiderar toda a problematização levantada pelos estudos em Linguística Aplicada (RICHARDS, 2001; CRAWFORD, 2002; GRIGOLETTO, 1999; MACHADO, 1996), entendemos que o material em si não se constitui como elemento engessador, já que é sobretudo o olhar do professor, balizado por suas concepções de ensino-aprendizagem, que incidirá nas formas como o material será trabalhado na aula (MAGNO E SILVA, 2009).

Outro ponto levantado, durante as reuniões pedagógicas, diz respeito à dificuldade tanto de se usar um material produzido pelo outro quanto a de se produzir um material para que outro use. Desse modo, o enunciado o material didático só pode ser eficientemente usado Olhares \& Trilhas $\mid$ Uberlândia | vol.20, n. 3 | set/dez. 2018 - ISSN 1983-3857 
Brito; Silveira | p. 44- $60 \quad$ Ensino e autoria: Sobre a elaboração de material didático para um curso...

pelo próprio professor que o produziu aponta, a nosso ver, para a ilusão de controle e também de completude do sujeito, ao se ver como detentor de sentidos de seu próprio material, como se os sentidos (de seu próprio dizer) também não lhe escapassem ou como se o uso do material pelo professor - ainda que autor - não se constituísse sempre como um evento único e irrepetível.

Por fim, alguns professores argumentaram que não viam muito sentido no projeto, uma vez que, na visão deles, era algo que já faziam ao prepararem as aulas. Desse modo, o terceiro enunciado - já produzo material didático - possibilitou a discussão, no grupo, da diferença entre o gênero 'plano de aula', 'slides para aula' e material didático, propriamente dito. O que parece ser apagado, na percepção de alguns professores, é justamente o fato de que a escrita do material o posiciona de forma distinta em relação à língua e ao próprio aluno. A escrita demanda que o professor: articule atividades didáticas em sequências lógicas, coerentes e coesas; tenha cuidado com o aspecto visual do material; atente para questões dos direitos autorais dos textos verbais e não verbais que utiliza; elabore enunciados suficientemente claros para serem utilizados por um outro professor. Enfim, a produção do material o interpela a se posicionar de forma a dar um 'acabamento' - ainda que ilusório na/pela língua outra, as suas propostas de ensino, o que não é demandado na elaboração de slides e/ou planos de aula. Uma simples imagem colocada em um slide requer toda uma elaboração linguístico-discursiva quando transposta para o material didático.

Outro aspecto que corrobora nossa percepção acerca da resistência, por parte de alguns, na produção do material didático diz respeito ao silenciamento sobre o projeto nas respostas ao questionário avaliativo, mencionado anteriormente. Dos dez professores, três não fizeram qualquer menção ao projeto, sendo que dois desses foram justamente os que levantaram boa parte das problematizações nas reuniões.

Ainda que, aparentemente, a resistência tenha sido uma voz minoritária, compreendemos sua relevância por trazer à tona a relação tenso-conflitiva que a tomada da palavra instaura ao sujeito, especialmente em uma língua outra, e em um gênero escrito acadêmico. Além disso, cabe mencionar o que observamos no que se refere à dinâmica da elaboração do material, propriamente dita. Após algumas reuniões, dividimos os três grupos em subgrupos e os orientamos a produzirem diferentes partes do material. Algumas duplas pareciam produzir menos, atendo-se mais aos aspectos de formatação do material do que à produção de atividades pedagógicas, por exemplo, o que parece acenar que a resistência não 
Brito; Silveira | p. 44- 60 Ensino e autoria: Sobre a elaboração de material didático para um curso...

se dá apenas naquilo que se explicita verbalmente. Ora não podemos desconsiderar que o questionário avaliativo foi solicitado pela coordenadora, instaurando, pela relação assimétrica de poder, espaços de interdição ao professor. Prova disso é que apenas um, dos dez professores, entregou seu material didático completo ao final do semestre, embora a maioria tenha avaliado o projeto como positivo. Esse fato nos levou a reformular as ações do projeto de modo a permitir que o material fosse produzido individualmente ou em duplas, conforme o curso ministrado pelo professor, e em horários que não os das reuniões pedagógicas.

\section{Considerações Finais}

Neste artigo, discutimos alguns resultados de um projeto de desenvolvimento de material didático para o ensino de LI com fins acadêmicos no NucLi-ISF-UFU. Retomando o título do trabalho - ensino e autoria - aventar-nos-íamos a dizer que a preparação de aula, e sua materialização em planos de aula e/ou slides, por exemplo, constitui-se já em um gesto de autoria, uma vez que demanda do professor um olhar que vem recortar, redimensionar, reorganizar a língua como objeto do saber. Todavia, nossas análises sugerem que a elaboração do material didático se constitui como processo tenso-conflitivo de produção e resistência, ao demandar dos professores bolsistas a inscrição em distintas posições discursivas, a saber: a de professores de língua inglesa e a de produtores de material. Se, para a primeira posição, a fala se configura como prática linguageira que organiza as interações verbais (ainda que fortemente relacionada à escrita, haja vista acontecer no contexto acadêmico), estabelecendo os "rituais" da aula, por meio, por exemplo, da canônica sequência IRA (Iniciação-RespostaAvaliação). Para a segunda posição, a escrita assume função central, interpelando o sujeito, a partir da relação de alteridade que estabelece com seu auditório social, a mobilizar e articular diferentes vozes e a costurar fios dispersos para construir uma unidade para seu material didático.

Instaurando a necessidade de um posicionamento em relação às palavras do outro, que, “introduzidas na nossa fala, são revestidas inevitavelmente de algo novo, da nossa compreensão e da nossa avaliação" (BAKHTIN, 2002, p. 195), a produção do material didático permite ao professor problematizar suas concepções de ensino-aprendizagem, revisitar as teorias que estuda no curso de Letras, enfim, lançar um gesto de autoria ao ensino, que, a nosso ver, pode reverberar em seu processo de formação profissional. 


\section{Referências}

BAKHTIN, M. (1953). Estética da criação verbal. Trad. Paulo Bezerra. São Paulo: Martins Fontes, 2003.

BAKHTIN, M. (Volochinov). (1929). Marxismo e Filosofia da Linguagem: problemas fundamentais do Método Sociológico na Ciência da Linguagem. Trad. Michel Lahud e Yara Frateschi Vieira. $7^{\text {a }}$ Ed. São Paulo: Hucitec, 2002.

BAKHTIN, M. O discurso em Dostoiévski. In: Problemas da poética de Dostoiévski. 3. ed. Rio de Janeiro: Forense Universitária, 2002.

BAKHTIN, M. Os gêneros do discurso. Trad. de Paulo Bezerra. São Paulo: Editora 34, 2016.

BRITO, C. C. P. Entretecendo vozes na (re)escrita de diários reflexivos de professores de línguas em formação inicial. Signum. Estudos de Linguagem, v. 15, n. 2, p. 65-83, 2012. https://doi.org/10.5433/2237-4876.2012v15n2p65

CELANI, M. A. A. A relevância da Linguística Aplicada na formulação de um Política Educacional Brasileira. In: FORTKAMP, M. B. M. Aspectos da Linguística Aplicada: estudos em homenagem ao professor Hilário Bohn. Florianópolis: Insular, 2008. p. 17-32

CRAWFORD, J. The role of materials in the language classroom: finding the balance. In: RICHARDS, J.C.; RENANDYA, W. A. Methodology in Language Teaching. Cambridge: Cambridge University Press, 2002. p. 80-91.

https://doi.org/10.1017/CBO9780511667190.013

FABRÍCIO, B. F. Processos de ensino-aprendizagem, educação linguística e descolonialidade. In: ZOLIN-VESZ, F. (Org.). Linguagens e descolonialidades: práticas linguageiras e produção de (des)colonialidades no mundo contemporâneo - vol. 2. Campinas, SP: Pontes Editores, 2017. p. 15-38.

FIAD, R. S. A escrita na Universidade. Revista da Abralin, v. 10, n. 4, p. 358-369, 2011. https://doi.org/10.5380/rabl.v10i4.32436

GRIGOLETTO, M. Seções de leitura no livro didático de língua estrangeira: lugar de interpretação? In: CORACINI, M. J. R. F. (Org.). Interpretação, autoria e legitimação do livro didático: língua materna e língua estrangeira. Campinas: Pontes, 1999. p. 79-91.

GUILHERME, M. F. F. Ensino de línguas estrangeiras e formação de professores: deslocamentos epistemo-pragmáticos numa perspectiva celaniana. In: SZUNDY, P. T. C. e BÁRBARA, L. Maria Antonieta Alba Celani e a Linguística Aplicada: pesquisadoresmultiplicadores em (inter)ações. Campinas: Mercado de Letras, 2013. p. 37-56.

HASHIGUTI, S. T. O corpo nas imagens em livros didáticos de língua inglesa: repetição e regularização de sentidos. In: HASHIGUTI, S. T. (Org.). Linguística aplicado ao ensino de línguas estrangeiras: práticas e questões sobre e para a formação docente. Curitiba: CRV, 2013. p. 35-54.

https://doi.org/10.24824/978858042755.4

KIRSCH, W.; SARMENTO, S. Stories of professional development in Brazilian Languages Without Borders Program. BELT - Brazilian English Language Teaching Journal, v. 9, n. 1, p. 115-132, 2018. 
Brito; Silveira | p. 44- $60 \quad$ Ensino e autoria: Sobre a elaboração de material didático para um curso...

MACHADO, N. J. Sobre livros didáticos: quatro pontos. In: BRASIL. INEP. Livro didático e qualidade de ensino. Em Aberto, Brasília, ano 16, n.69, 1996. Disponível em http://emaberto.inep.gov.br/index.php/emaberto/article/viewFile/1036/938. Acesso em $11 \mathrm{de}$ nov. de 2018.

MAGNO E SILVA, W. Livros didáticos: fomentadores ou inibidores da autonomização? In: DIAS, R. e CRISTÓVÃO, V. L. L. (Orgs.). O livro didático de língua estrangeira: múltiplas perspectivas. Campinas, SP: Mercado de Letras, 2009. p. 57-78.

MELO, L. C.; GONÇALVES, A.V.; SILVA, W. R. Escrita acadêmica na escrita reflexiva profissional: citações de literatura científica em relatórios de estágio supervisionado. Bakhtiniana: Revista de Estudos do Discurso, v. 8, n. 1, p. 95-119, 2013. https://doi.org/10.1590/S2176-45732013000100007

MOITA LOPES, L. P. (Org.). Lingüística Aplicada e vida contemporânea: problematização dos construtos que têm orientado a pesquisa. In:

Por uma linguiística aplicada

INdisciplinar. São Paulo: Parábola Editorial, 2006. p. 85-107.

PENNYCOOK, A. Beyond (F)utilitarianism: English "as" academic purpose. Hong Kong papers in linguistics and language teaching, 17, p. 13-23, 1994.

RICHARDS, J. C. The role and design of instructional materials. In: Curriculum Development in Language Teaching. Cambridge: Cambridge University Press, 2001. p. 251-285.

https://doi.org/10.1017/CBO9780511667220.010

SALAS, M. R. English Teachers as Materials developers. Actualidades Investigativas enEducación, v.4, n. 2, p. 1-17, 2004. Disponível em https://www.researchgate.net/publication/26429759_English_Teachers_as_materials_develop ers Acesso em 09 de nov. de 2018.

SARMENTO, S., KIRSCH, W. Inglês Sem Fronteiras: uma mirada ao contexto de prática pelo prisma da formação de professores a partir do trabalho docente. Ilha do Desterro, v. 68, n. 1, p. 47-59, 2015.

https://doi.org/10.5007/2175-8026.2015v68n1p47

SARMENTO, S.; ABREU-E-LIMA, D.; MORAES FILHO, W. (Orgs.). Do Inglês sem Fronteiras ao Idiomas sem Fronteiras. Belo Horizonte: Editora UFMG, 2016.

TOMLINSON, B. Materials development for language learning and teaching. Language Teaching, 45, p. 143-179, 2012.

https://doi.org/10.1017/S0261444811000528 